\title{
Localization of the Carotid Bifurcation According to Hyoid Bone and Mandibular Angle
}

\author{
Localización de la Bifurcación Carotídea Según el Hueso Hióides y el Ángulo Mandibular
}

Kurkcuoglu Ayla ${ }^{1}$; Pelin Can'; Oktem Hale ${ }^{1} \&$ Aytekin Cuneyt ${ }^{2}$

KURKCUOGLU, A.; PELIN, C.; OKTEM, H. \& AYTEKIN, C. Localization of the carotid bifurcation according to hyoid bone and mandibular angle. Int. J. Morphol., 35(3):901-906, 2017.

SUMMARY: The aim of this study was to determine the carotid bifurcation level in relation with the hyoid bone and mandibular angle. Common carotid artery is the largest artery in the neck, and it gives off two terminal branches, namely external and internal carotid arteries. The bifurcation level of it shows variations, however it is usually situated at the level of C4 vertebra or at the upper border of thyroid cartilage. On the other hand, carotid bifurcation may be situated as low as T3 vertebra, or as high as the level of hyoid bone. In this study, conventional angiographic images of 112 patients were used. The distances of carotid bifurcation to hyoid bone and mandibular angle were measured on those images. In addition, right and left side difference was determined. The distance of carotid bifurcation level to the mandibular angle was measured as $21.26 \pm 8.57 \mathrm{~mm}$ on the right and $20.25 \pm 8.75 \mathrm{~mm}$ on the left side in males, and $19.72 \pm 8.89$ on the right, and $18.5 \pm 9.25 \mathrm{~mm}$ on the left side in females. Distance between the carotid bifurcation level and hyoid bone ranged 1.94 $\pm 12.69 \mathrm{~mm}$ in female and $3.04 \pm 9.00 \mathrm{~mm}$ in male on the left side. Having information about the level of carotid bifurcation is important in surgical and radiological procedures for determining the appropriate surgical procedure, and to prevent complications. We believe that the results of this study will shed light to planning of all interventions concerning common carotid artery.

KEY WORDS: Carotid bifurcation; Hyoid bone; Mandibular angle; Digital angiography.

\section{INTRODUCTION}

Carotid artery surgery is quite dangerous, and therefore it is important to have information about the anatomical structures in this region (Anu et al., 2007; Snell, 2012). There are controversies about the relation of common carotid artery (CCA) and its neighboring structures (Anu et al.; Snell; Barnett et al., 1998). It is important to have information about the anatomy and the level of carotid bifurcation $(\mathrm{CB})$ before surgical procedures and interventions of CCA to minimize morbidity and mortality. CCA is the largest artery in the neck. Although it originates from different arteries on the right and left sides of the neck, it usually bifurcates at the level of upper border of thyroid cartilage (Snell; Barnett et al.; Moore \& Dalley, 1999). Right CCA usually takes its origin at the level of sternoclavicular joint, however its origin may be at a superior level in $12 \%$ of the cases, or it may originate as a separate artery from the aortic arch (Vitek \& Reaves, 1973). Boyd (1934) has stated that a low CB results if external carotid artery (ECA) originates from third aortic arc, close to the aortic sac. Moffat (1959) suggested that third aortic arc contributed only to the first part of internal carotid artery (ICA), and CCA and ECA originated from aortic sac, and this was the reason for the variations. A left CCA arising from brachiocephalic trunk is a frequently seen variation. In this case, bifurcation is situated at an upper level, at the level of hyoid bone. Occasionally, $\mathrm{CB}$ is situated at the level of midpoint of larynx, or at the level of inferior border of cricoid cartilage. Some authors reported that CCA run in the neck without giving off its terminal branches, or its terminal branches directly originated from aortic arch (Boyd; Anangwe et al., 2008).

The variations of CCA are encountered in angiographic images, cadaver dissections, and surgical procedures. Although the level of CB is usually asymmetrical on the left and right sides, it is situated at the level of $\mathrm{C} 6-\mathrm{C} 7$ on the right, and at the level of C5-C6 on the left side (Gulsen et al., 2009; Kurkcuoglu et al., 2015). Sasaki et al. (2013) reported that CCA did not branch off in a 68-year-old male, as seen on preoperative angiography. Mayama et al., noted that abnormalities of aortic arch might cause blood supply

${ }^{1}$ Department of Anatomy, Faculty of Medicine, Baskent University, Ankara, Turkey.

${ }^{2}$ Department of Radiology, Faculty of Medicine, Baskent University, Ankara, Turkey. 
problems in brain, since it might change blood flow pattern of the cerebral arteries (Manyama et al., 2011). Having information about the possible variations of CCA and external carotid artery is quite important in head and neck surgery (Prajakta et al., 2011). Close neighborhood is important particularly for the surgical procedures of recurrent laryngeal nerve, vertebral artery, and thyroid gland (Gulsen et al.).

In this study, we aimed to determine the variations of CB level in relation with two different reference points, analyze the differences between right and left sides, and investigate the relation between level of $\mathrm{CB}$ and the length of neck.

\section{MATERIAL AND METHOD}

All measurements were performed retrospectively on conventional angiography images of 112 patients (70 males, 42 females) between the ages of 22 and 91 years, in Radiology Department of Baskent University Faculty of Medicine. Our study was approved by Institutional Review Board (KA 14/19). Digital subtraction angiography (DSA) device (Siemens Artis Zee monoplan) was used in all patients. The patients were prepared for the procedure under standard sterile conditions, while they were lying on the angiography table. Following local anesthesia, a $4 \mathrm{~F}$ or $5 \mathrm{~F}$ introducer was placed into the right or left common femoral artery. A 4F pig-tail catheter glide was advanced into the aortic arch through the guidewire, and aortic arch aortography was performed. Later, the branches were selectively catheterized with Simon 1 and Simon 2 catheters. The images obtained were installed into CT Leonardo, MR Satellite work stations, and the measurements were made. The patients' heads were held still in neutral position using a strap, all through the procedure. Radiograms obtained in all other positions (hyperextension, lateral rotation etc.) except neutral position were excluded from the study. In each patient, lateral (left or right) and oblique (left or right) radiograms were obtained during selective CCA injections. In some cases, an anteroposterior radiogram was also obtained.

The same investigator determined the distance of CB to the mandibular angle and body of hyoid bone on both sides (Fig. 1). The distance between the mandibular angle and midpoint of the clavicle was used to measure the length of neck. The patients who had neck surgery or interventions directed to CCA or its branches were excluded from the study. In addition, presence of hyperextension or excessive lateral rotations of the neck during the procedure were regarded as exclusion criteria.
Statistical analysis. The analysis of data was performed with SPSS 17.0 (SPSS Ver. 17.0, Chicago IL, USA) statistical package program. The normality of distribution of the variables was analyzed with Shapiro-Wilk test. The homogeneity of the group variances was analyzed with Levene test. Student's t- test was used for comparison of the means of parametric variables between two independent groups. The means of two dependent groups were compared using paired t- test. The medians of two independent groups' variables that did not fulfill the prerequisites for the parametric tests were compared with Mann Whitney U test. The medians of dependent groups were compared with Wilcoxon test. The correlations among the variables were analyzed with Spearman rho correlation coefficient. The categorical variables were presented as frequency (n) and percent (\%). $\mathrm{P}<0.05$ was regarded as statistically significant.

\section{RESULTS}

The bifurcation level of the CCA was analyzed on the angiography images of 70 males and 42 females. The ages of the females ranged between 32 and 90 years $(71.34$ \pm 10.21 years), and the ages of the males ranged between 22 and 82 years (71.24 \pm 11.34 years). The neck length was $57-114 \mathrm{~mm}(76.60 \pm 11.03 \mathrm{~mm})$ in female and $45-108$ $\mathrm{mm}(75.70 \pm 10.14 \mathrm{~mm})$ in males, without any statistically significant difference between the genders ( $\mathrm{p} \geq 0.05)$ (Table I).

All measurements were performed bilaterally, and it was found that $\mathrm{CB}$ was at the level of the mandibular angle or below it in all patients. The results are presented in Table II. CB was exactly at the level of the mandibular angle in 2 women and in one man on the right side, and in one woman and in two men on the left side. CB- the mandibular angle was found longer in men compared to women on the both sides. There was no difference between the right and left sides for distance of $\mathrm{CB}$ to the mandibular angle ( $\mathrm{p}=0.349$ for males and $\mathrm{p}=0.417$ for females).

The position of $\mathrm{CB}$ in relation with hyoid bone was analyzed: 0 indicated a $\mathrm{CB}$ at the level of hyoid bone, $(+)$ indicated a CB above the level of hyoid bone, and (-) indicted a $\mathrm{CB}$ below the level of hyoid bone. When all patients were taken into consideration, $\mathrm{CB}$ was at the level of the hyoid bone in $39.0 \%$, below it in $25.0 \%$, and above it in $36.0 \%$ of the patients on the right side. On the left side, $\mathrm{CB}$ was at the level of hyoid bone in $31.0 \%$, below it in $23.0 \%$, and above it in $46 \%$ of the patients. The differences were not statistically significant $(p=0.176$ for 
Table I. The age (year) and neck lengths ( $\mathrm{mm}$ ) of the patients.

\begin{tabular}{|c|c|c|c|}
\hline & $\begin{array}{l}\text { Female } \\
(n=42)\end{array}$ & $\begin{array}{c}\text { Male } \\
(n=70)\end{array}$ & $\mathrm{p}$ \\
\hline Age (years) & $71.34 \pm 10.21$ & $71.24 \pm 11.34$ & 0.501 \\
\hline $\begin{array}{l}\text { Mean } \pm \text { SD } \\
\text { Median (min-max) }\end{array}$ & $73.50(37-81)$ & $76.00(22-82)$ & \\
\hline $\begin{array}{l}\text { Neck length }(\mathbf{m m}) \\
\text { Mean } \pm \text { SD } \\
\text { Median (min-max) }\end{array}$ & $76.60 \pm 11.03$ & $\begin{array}{r}75.70 \pm 10.14 \\
77.50(45-108)\end{array}$ & 0.892 \\
\hline
\end{tabular}

males, and $\mathrm{p}=0.905$ for females). $\mathrm{CB}$-hyoid bone is presented in Table II. CB was above the level of hyoid bone only in 6 men on the right side, and it was below the level of hyoid bone on the left side.

The CB levels were asymmetrical in 7 (6.25 $\%$ ) males in relation to the level of the hyoid bone on the right and the left sides. The CB level was below the level of the hyoid bone on the right side, and it was above the level of hyoid bone on the left side in 3 of those patients. In addition, CB level was above the level of the hyoid bone on the right side, and below the level of the hyoid bone on the left side in 4 male patients. This situation was not observed in female participants.

We analyzed the relation of neck length with the distance of $\mathrm{CB}$ to the mandibular angle. We calculated the mandibular angle / neck length for this purpose. This ratio was $1 / 3.62$ on the right and $1 / 3.80$ on the left side in women, and 1/3.95 on the right and $1 / 4.01$ on the left side in men. As a practical result, we may say that $\mathrm{CB}$ is situated at the intersection point of upper $1 / 4$ and lower $3 / 4$ of the neck.

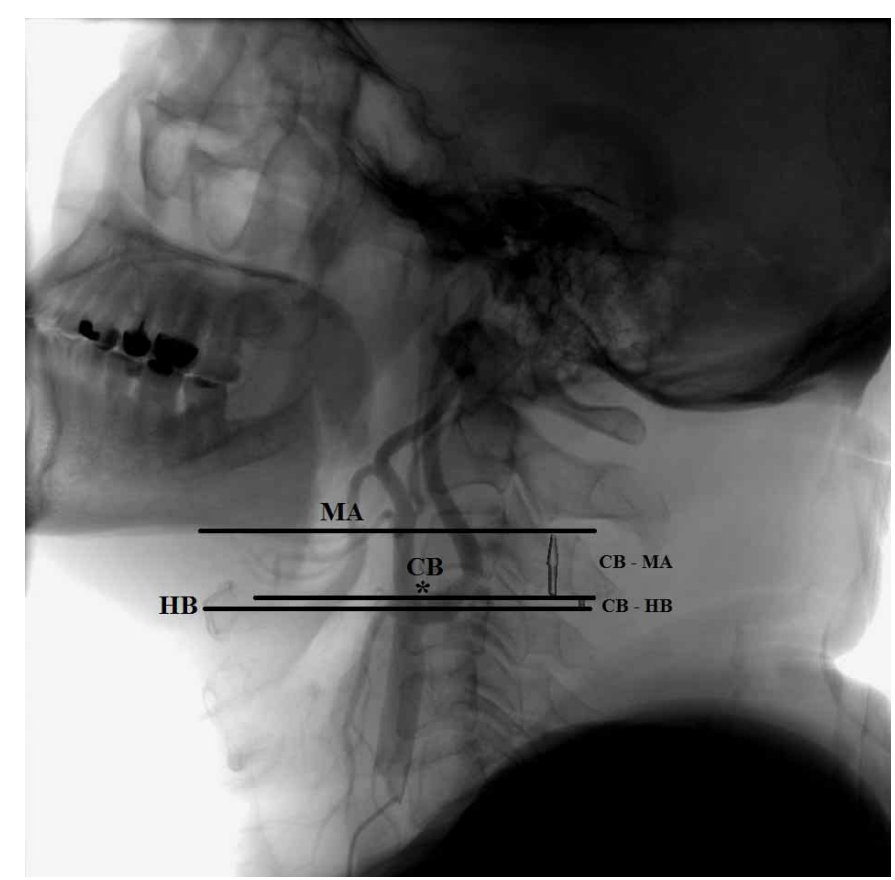

Fig. 1. Localization of the carotid bifurcation according to hyoid bone and mandibular angle. MA: mandibular angle, HB: hyoid bone, CB: carotid bifurcation, CB-MA: the distances of carotid bifurcation to mandibular angle, CB-HB: the distances of carotid bifurcation to hyoid bone.

Table II. The distances $(\mathrm{mm})$ of carotid bifurcation to the mandibular angle and hyoid bone.

\begin{tabular}{lcccccc}
\hline & \multicolumn{2}{c}{ CB - The mandibular angle $(\mathrm{mm})$} & & \multicolumn{2}{c}{ CB - Hyoid bone (mm) } \\
& $\begin{array}{c}\text { Right side } \\
\text { Mean } \pm \text { SD }\end{array}$ & $\begin{array}{c}\text { Left side } \\
\text { Mean } \pm \text { SD }\end{array}$ & $p$ & Right side & Left side & p \\
& Median (min-max) & Median (min-max) & & $\begin{array}{c}\text { Mean } \pm \text { SD } \\
\text { Median(min-max) }\end{array}$ & $\begin{array}{c}\text { Mean } \pm \text { SD } \\
\text { Median(min-max) }\end{array}$ & \\
\hline emale & $19.72 \pm 8.89$ & $18.5 \pm 9.25$ & 0.417 & $2.31 \pm 9.08$ & $1.94 \pm 12.69$ & 0.905 \\
$\mathrm{l}=42)$ & $22.00(0-36)$ & $19.50(0-35)$ & & $0.00(-16-25)$ & $0.00(-34-34)$ & \\
Iale & $21.26 \pm 8.57$ & $20.25 \pm 8.75$ & 0.349 & $2.32 \pm 9.51$ & $3.04 \pm 9.00$ & 0.176 \\
$\mathrm{l}=70)$ & $21.00(0-44)$ & $20.00(0-38)$ & & $0.00(-24-28)$ & $0.00(-20-28)$ & \\
\hline
\end{tabular}

\section{DISCUSSION}

In this study, the level of $\mathrm{CB}$ was determined in relation with the mandibular angle and hyoid bone in 112 patients. Previous studies usually determined the level of
$\mathrm{CB}$ in relation with the levels of cervical vertebrae (Anangwe et al.; Gulsen et al.; Klosek \& Rungruang, 2008). However, no studies up to date investigated two reference points we 
used together, or showed the relation between neck length and mandibular angle in relation with CB level. Variations of CCA are clinically important in a number of surgical procedures including ligation of external carotid artery, intra-arterial administration of chemotherapeutic agents, interpretation of digital subtraction angiography, and during radical neck dissection (Gluncic et al., 2001; Riles et al., 1993). Most dissertations have stated that CCA bifurcates at the level of the superior border of thyroid cartilage (Klosek \& Rungruang; Kurkcuoglu et al.; Moore \& Dalley). Ito et al. (2006) reported a high common CB in 25 (31.2\%), a standard bifurcation (C4) in $46(57.5 \%)$, and low bifurcation in $9(11.3 \%)$ patients in their series of 80 cases.

Less commonly, authors described that CCA most commonly bifurcated at the tip of the greater horn of the hyoid bone (Morimoto et al., 1990). The hyoid bone may be palpated a few centimeters below and behind the chin, especially if the neck is extended. It may be palpated between the finger and thumb, and moved from side to side. The hyoid bone lies approximately at the level of third cervical vertebra (Stranding, 2005).

Prajacta et al., reported that left and right CB were situated $1 \mathrm{~cm}$ above the level of hyoid bone in a 72-year-old, male cadaver (Prajakta et al., 2011). Anangwe et al. found that CCA bifurcated at a high level in $63.8 \%$ of the cadavers, and the right CCA originated at a higher level in $10 \%$, and at a lower level in $2.6 \%$ of the cadavers studied. Prajakta et al., used hyoid bone as a reference point for $\mathrm{CB}$, and determined that the distance between CB and horn of hyoid bone was 1 $\mathrm{cm}$ on both sides. In may be seen that the results of all aforementioned studies are similar. In our study, the distance between CB and hyoid bone was found as $2.31 \pm 9.08 \mathrm{~mm}$ on the right, and $1.94 \pm 12.69 \mathrm{~mm}$ on the left side in women, and as $2.32 \pm 9.51 \mathrm{~mm}$ on the right and $3.04 \pm 9.00 \mathrm{~mm}$ on the left side in men. In men, CB was situated at a lower level on both sides. Our results were different from the other studies in the literature, because we did not measure the distance of CB to the greater horn of the hyoid bone, but to the midline of the body of the hyoid bone. We accepted this point as the reference point because the body of the hyoid bone may be more clearly identified on physical examination of neck, and structural alterations of the greater horn of hyoid bone on the right and left sides might cause different measurements.

Lo et al. (2006) performed a study on 36 cadavers, and found that the CCA bifurcated at the level of the body of the hyoid bone in $15(88.9 \%)$, at the superior border of thyroid cartilage in $11(42.3 \%)$, and at the tip of the greater horn of hyoid bone in 8 (15\%) cadavers. In 15 of 31 cadavers (48\%), the levels of CCA bifurcation were asymmetrical between the left and right sides. In an angiographic study, Morimoto et al. emphasized that CB was usually situated at the level of $\mathrm{C} 4$ or above thyroid cartilage; however it might be as low as T3 vertebra or as high as superior to the hyoid bone. In our study, we analyzed both sides in 112 angiography images, and CB was seen above the hyoid bone in $46 \%$, at the level of the body of the hyoid bone in $31 \%$, and below the hyoid bone in $23 \%$ of the cases. Those results are similar to the results of Lo et al.

Gulsen et al. reported that the level of CB was asymmetrical on the left and right sides (at C6-C7 on the right side, and between $\mathrm{C} 5$ and $\mathrm{C} 6$ on the left side), and therefore one must be careful of the difference between the right and the left sides. An asymmetrical CB level was reported in $48 \%$ of the cases by Lo et al., in $33 \%$ of females and $22 \%$ of the males by Klosek \& Rungruang, and in $37.5 \%$ of the cases by Ito et al.

In our study, we found that the CB levels were asymmetrical in only 7 male patients, however such an asymmetry was not seen in females. Referring different levels of $\mathrm{CB}$ on the right and the left sides as "asymmetry" may be disputed; however CB localization was different on two sides in $6.25 \%$ of the patients. In addition, in our study, we did not observe any asymmetry in relation with the mandibular angle. All CB were at the level of the mandibular angle, or below it.

Klosek \& Rungruang analyzed the level of CB in relation with the cervical vertebrae (particularly $\mathrm{C} 4$ ), thyroid cartilage, and angle of mandible.

They reported that CB level was asymmetrical in 33\% of males and $22 \%$ of females, and there was no bifurcation in four cadavers. They also stated that the most frequently seen level was $\mathrm{C} 4$, the localization was not the same on the right and the left sides, it was usually $6 \mathrm{~mm}$ superior to the thyroid cartilage, and angle of mandible could be used as a reference point (Klosek \& Rungruang). The authors reported that CB level was at a more inferior level in males, without any difference in the left or the right sides. Further, CB in the sample population was located below gonion (Go) of the mandible, and the CB-Go measurements varied from 1.0 to $4.8 \mathrm{~cm}$ in women, and from 1.0 to $6.5 \mathrm{~cm}$ in men. Mean CBGo distances were as follows: $3.3 \pm 0.8 \mathrm{~cm}$ (right) and $3.1 \pm$ $1.2 \mathrm{~cm}$ (left) in women, and $3.5 \pm 0.9 \mathrm{~cm}$ (right) and $3.9 \pm 1.2$ $\mathrm{cm}$ (left) in men. Measurements of CB-Go on the left sides were significantly different in studied gender groups $(\mathrm{P}=0.02)$; however, no statistical difference was found within each group for both sides. The CB-Go distance may be more useful in clinic due to easy evaluation. The Doppler ultrasound techniques indicated wide variability of $\mathrm{CB}$ location ranging from 0 to $7 \mathrm{~cm}$ below the gonion point, and the mean distance was $3.2 \pm 0.1 \mathrm{~cm}$ on the right side of the neck, and $3.6 \pm 0.2$ 
$\mathrm{cm}$ on the left side, without a regard to gender (Schulz \& Rothwell, 2001). Our result were similar to this study, however $\mathrm{CB}$ - the angle of the mandible- gonion was $19.72 \pm 8.89 \mathrm{~mm}$ on the right and $18.5 \pm 9.25 \mathrm{~mm}$ on the left side in women, and $21.26 \pm 8.57 \mathrm{~mm}$ on the right and $20.25 \pm 8.75 \mathrm{~mm}$ on the left side in men. Therefore, we found that $\mathrm{CB}$ level was closer to the angle of mandible without any difference between right and left sides. In our study, we also measured the lengths of the necks. The neck lengths were bilaterally longer in men (Table I). We determined the location of $\mathrm{CB}$ in relation with the neck length and its distance to angle of the mandible. We found that $\mathrm{CB}$ was situated at the at the intersection point of $1 / 4$ upper and 3/4 lower parts of the neck in both genders. We could not compare our results with the results of other studies, since no such studies were performed before. However, we believe that this information is practical, and it will contribute to clinicians and surgeons.

It is extremely rare for the CCA to give off multiple branches in the neck without undergoing a bifurcation (Morimoto et al.; Nishizawa et al., 1986). Ooigawa et al. (2006) reported a similar condition in a 67-year-old female, and reported rupture of aneurysm one month after angiography. In our study, we did not see any non-bifurcated CCA. CB is the most frequent site for atherosclerotic plaque formation. Moreover, alteration of the carotid sinus pressure resulting from neck palpation or electric stimulation may cause carotid baroreflex (Filippone \& Bisognano, 2007). In addition, CCA is an important landmark in head and neck surgery, defining the plane of dissection during neck dissection (Lucev et al., 2000). Conventional angiography has been considered as the most accurate technique for evaluating internal changes in $\mathrm{CB}$, such as stenosis, however predicting the location of $\mathrm{CB}$ level and external anatomical landmarks which can be clinically used, remains an important goal on external physical examination of neck (Schulz \& Rothwell). We designed this study to serve this purpose.

\section{CONCLUSION}

In conclusion, having information about the $\mathrm{CB}$ level variations is important for carotid endarterectomy, catheterizations, radical neck dissections, vascular aneurysms, and vascular surgical interventions in the neck. In addition, having information about any abnormal branching is necessary for the diagnosis and treatment of intracranial aneurysms. We believe, that the results of this study will shed light to planning of all interventions concerning CCA and its branches, as well as all surgical procedures performed in the neck, taking the right and left sides into consideration, and will help to minimize complications. The clinically prevailing variations of the level of carotid artery bifurcation should be regarded by surgeons performing procedures in head and neck area. Some others as carotid sinus stimulation should also be discussed before, and during its surgery. In addition, physicians, radiologists, anesthesiologists and nurses should pay more attention to vital sign monitoring and thorough preparations for emergency surgical procedures that involve manipulation of the carotid sinus. We believe that the results of this study will support the role of the operating theatre nurse and demonstrates the impact that nurse-patient relationships can have on patient experience.

\section{ACKNOWLEDGEMENTS}

The authors express their gratitude to Department of Biostatistics, Faculty of Medicine at Baskent University for her help with statistical analysis, and Term V students at Baskent University Faculty of Medicine, for their help with the measurements.

KURKCUOGLU, A.; PELIN, C.; OKTEM, H. \& AYTEKIN, C. Localización de la bifurcación carotídea según el hueso hióides y el ángulo mandibular. Int. J. Morphol., 35(3):901-906, 2017.

RESUMEN: El objetivo de este estudio fue determinar el nivel de bifurcación carotídea en relación con el hueso hioides y el ángulo de la mandíbula. La arteria carótida común es la arteria más grande del cuello, y tiene dos ramas terminales, las arterias carótidas externa e internas. El nivel de bifurcación muestra variaciones, sin embargo suele situarse a nivel de la cuarta vértebra cervical o en el margen superior del cartílago tiroideo. Por otro lado, la bifurcación carotídea puede estar situada tan baja como a nivel de la tercera vértebra torácica, o tan alta como a nivel del hueso hioides. En este estudio se utilizaron imágenes angiográficas convencionales de 112 pacientes. Se midieron las distancias de la bifurcación carotídea con el hueso hioides y el ángulo de la mandíbula en esas imágenes. Además, se determinó la diferencia entre los lados derecho e izquierdo. La distancia entre el nivel de bifurcación carotídea y el ángulo de la mandíbula se midió, siendo de $21,26 \pm 8,57 \mathrm{~mm}$ a la derecha y $20,25 \pm 8,75 \mathrm{~mm}$ en el lado izquierdo, en los hombres, y 19,72 $\pm 8,89$ a la derecha y 18,5 $\pm 9,25$ $\mathrm{mm}$ a la izquierda en mujeres. La distancia entre el nivel de bifurcación de la carótida y el hueso hioides osciló entre 1,94 \pm 12,69 $\mathrm{mm}$ en mujeres y, 3,04 $\pm 9,00 \mathrm{~mm}$ en hombres, en el lado izquierdo. La información sobre el nivel de bifurcación carotídea es importante en los procedimientos quirúrgicos y radiológicos para determinar el procedimiento quirúrgico apropiado y prevenir complicaciones. Creemos que los resultados de este estudio arrojarán luz a la planificación de las intervenciones relacionadas con la arteria carótida común.

PALABRAS CLAVE: Bifurcación carotídea; Hueso hioides; Ángulo de la mandíbula; Angiografía digital. 


\section{REFERENCES}

Anangwe, D.; Saidi, H.; Ogeng'o, J. \& Awori, K. O. Anatomical variations of the carotid arteries in adult Kenyans. East Afr. Med. J., 85(5):244-7, 2008.

Anu, V. R.; Pai, M. M.; Rajalakshmi, R.; Latha, V. P.; Rajanigandha, V. \& D'Costa, S. Clinically-relevant variations of the carotid arterial system. Singapore Med J., 48(6):566-9, 2007.

Barnett, H. J.; Taylor, D. W.; Eliasziw, M.; Fox, A. J.; Ferguson, G. G.; Haynes, R. B.; Rankin, R. N.; Clagett, G. P.; Hachinski, V. C.; Sackett, D. L.; Thorpe, K. E.; Meldrum H. E.; \& Spence J. D. Benefit of carotid endarterectomy in patients with symptomatic moderate or severe stenosis. North American Symptomatic Carotid Endarterectomy Trial Collaborators. N. Engl. J. Med., 339(20):1415-25, 1998.

Boyd, J. D. Absence of the right common carotid artery. J. Anat., 68(Pt. 4):551-7, 1934.

Filippone, J. D. \& Bisognano, J. D. Baroreflex stimulation in the treatment of hypertension. Curr. Opin. Nephrol. Hypertens., 16(5):403-8, 2007.

Gluncic, V.; Petanjek, Z.; Marusic, A. \& Gluncic, I. High bifurcation of common carotid artery, anomalous origin of ascending pharyngeal artery and anomalous branching pattern of external carotid artery. Surg. Radiol. Anat., 23(2):123-5, 2001.

Gulsen, S.; Caner, H. \& Altinors, N. An anatomical variant : low-lying bifurcation of the common carotid artery, and its surgical implications in anterior cervical discectomy. J. Korean Neurosurg. Soc., 45(1):32-4, 2009.

Ito, H.; Mataga, I.; Kageyama, I. \& Kobayashi, K. Clinical anatomy in the neck region--the position of external and internal carotid arteries may be reversed. Okajimas Folia Anat. Jpn., 82(4):157-67, 2006.

Klosek, S. K. \& Rungruang, T. Topography of carotid bifurcation: considerations for neck examination. Surg. Radiol. Anat., 30(5):383-7, 2008.

Kurkcuoglu, A.; Aytekin, C.; Oktem, H. \& Pelin, C. Morphological variation of carotid artery bifurcation level in digital angiography. Folia Morphol. (Warsz.), 74(2):206-11, 2015.

Lo, A.; Oehley, M.; Bartlett, A.; Adams, D.; Blyth, P. \& Al-Ali, S. Anatomical variations of the common carotid artery bifurcation. A. N. Z. J. Surg., 76(11):970-2, 2006.

Lucev, N.; Bobinac, D.; Maric, I. \& Drescik, I. Variations of the great arteries in the carotid triangle. Otolaryngol. Head Neck Surg., 122(4):590-1, 2000.

Manyama, M.; Rambau, P.; Gilyoma, J. \& Mahalu, W. A variant branching pattern of the aortic arch: a case report. J. Cardiothorac. Surg., 6:29, 2011.

Moffat, D. B. Developmental changes in the aortic arch system of the rat. Am. J. Anat., 105(1):1-35, 1959.

Moore, K. L. \& Dalley, A. F. Clinically Oriented Anatomy. $4^{\text {th }}$ ed. Philadelphia, Lippincott Williams \& Wilkins, 1999. pp.124-7.

Morimoto, T.; Nitta, K.; Kazekawa, K. \& Hashizume, K. The anomaly of a non-bifurcating cervical carotid artery. Case report. J. Neurosurg., 72(1):130-2, 1990.

Nishizawa, S.; Yamamoto, S.; Sugiura, Y. \& Uemura, K. Agenesis of the internal carotid artery with an unusual collateral pathway. No Shinkei Geka, 14(8):1011-5, 1986.

Ooigawa, H.; Nawashiro, H.; Fukui, S.; Tsuzuki, N.; Katoh, H.; Kawaguchi, T.; Kaneko, Y.; Tsutsumi, M.; Kawano, T. \& Shima, K. Non-bifurcating cervical carotid artery. J. Clin. Neurosci., 13(9):944-7, 2006.

Riles, T. S.; Berenstein, A.; Fisher, F. S.; Persky, M. S. \& Madrid, M. Reconstruction of the ligated external carotid artery for embolization of cervicofacial arteriovenous malformations. J. Vasc. Surg., 17(3): 491-8, 1993.

Sasaki, T.; Nagashima, H.; Oya, F.; Satoh, D. \& Kobayashi, S. Carotid artery stenting for atherosclerotic stenosis associated with non-bifurcating cervical carotid artery. Neurol. Med. Chir., 53(4):228-32, 2013.
Schulz, U. G. \& Rothwell, P. M. Major variation in carotid bifurcation anatomy: a possible risk factor for plaque development? Stroke, 32(11):2522-9, 2001.

Snell, R. S. Clinical Anatomy by Regions. $9^{\text {th }}$ ed. Philadelphia, Lippincott Williams \& Wilkins, 2012. pp.596-99.

Stranding, S. Gray's Anatomy. The Anatomical Basis of Clinical Practice. $39^{\text {th }}$ ed. Edinburgh, Elsevier Churchill Livingstone, 2005. pp.443-4.

Vitek J. J. \& Reaves, P. Thoracic bifurcation of the common carotid artery. Neuroradialogy, 5(3):133-9, 1973.

\section{Corresponding author:}

MD. PhD Kurkcuoglu Ayla

Department of Anatomy

Faculty of Medicine

Baskent University, 06530

Baglıca Ankara

TURKEY

\section{E-mail: kayla@baskent.edu.tr drakurkcuoglu@hotmail.com}

Received:15-12-2016

Accepted:05-04-2017 